\title{
Postharvest Challenges for Organically Grown Orchard Fruit
}

\author{
Penelope Perkins-Veazie \\ USDA-ARS, South Central Agricultural Research Laboratory, 911 Highway 3 West, Lane, OK 74555 \\ Gene Lester \\ USDA-ARS, SARC, Crop Quality and Fruit Insects Research Unit, 2413 E. Highway 83, \\ Building 200, Weslaco, TX 78596
}

Additional index words. production system, grapefruit, antioxidant, National Organic Program

\begin{abstract}
Switching from conventional to organic production requires a philosophical shift and recognition of different production system inputs plus postharvest handling challenges. First, and most obvious, is the replacement of common and readily available manufactured chemical inputs with approved "natural" or "nature-made compounds" (i.e., organic) for organic production. Many of these organic inputs may require new knowledge for successful implementation or may be less effective than conventional counterparts. Good orchard practices (e.g., cleanliness, bookkeeping) must be followed in an organic system just as they are in a conventional system. In addition, if processing (cider, sauces, or frozen fruit-sectioning preparations) is going to be part of the harvested operation, approved organic products will have to be used, and strict guidelines followed and documented. Organic versus conventional production system inputs can affect changes in the phytochemical and nutrient content of foods, and even change ripening patterns, which can affect harvest operations, marketing qualities, and consumer acceptance.
\end{abstract}

For both conventional and organic production systems, market-quality factors are the same. Fruit should be free of injury and decay, have appropriate color and shape, and have typical texture and flavor. Although consumers may be willing to overlook a few blemishes at fruit stands or farmers' markets, retail market-destined fruit must be of good quality and of varietal recognition. For example, 'Red Delicious' apples should be fully red and of elongated shape, not green and round. Fruit with puncture wounds or bruising leads to fungal colonization and must be regularly culled to eliminate contamination of adjacent fruit and to retain food safety. Retail-marketed fruit need to be of U.S. Department of Agriculture (USDA) No. 1 or Fancy grades for production-type fruits because competition for purchasing needs to justify not only the price differential on the one hand, but the pesticide residue issues on the other.

\section{POSTHARVEST HANDLING PRACTICES}

Postharvest and handling systems of cleanliness and temperature storage are generally the same for conventional and organic orchards, and good practices must be followed and documented (Suslow, 2000). Fruit should be of the proper maturity. Depending on the species, a crop may ripen earlier or later in an organic system compared with a conventional system. Thus, if organic fruit are being handled and stored for the first time, careful monitoring of the fruit should be done for the first few production and handling cycles until a clear ripening or storage protocol pattern emerges. Effective cooling should be done in both systems.

In a certified organic system, integrity of the organic product must be maintained from orchard to consumer. The most important

Received for publication 12 Jan. 2007. Accepted for publication 17 May 2007. aspect of this is that an organic system plan must be in place and adhered to, and records must be maintained. No comingling of organic and conventional products is allowed. Although this rule doesn't prevent organic and conventional produce being shipped in the same semi truck, it does mandate that organic fruit be packed in separate boxes preventing contact with conventional products and be labeled as organic. In addition, the packaging materials for organic fruit cannot contain prohibited substances. For instance, packing material impregnated with a nonorganic, but U.S. Food and Drug Administration-approved fungicide allowable for conventional produce, cannot be used in organic produce packaging systems (Federal Register, 2006).

Conventional practices and chemicals acceptable for use in a postharvest organic program include controlled-atmosphere (CA) storage, sulfur dioxide, and ethylene gas (Table 1). Chlorine, which is used extensively in conventional systems for washing produce, can be used for organic systems if the residual chlorine level does not exceed 4 ppm. Substances allowed under conventional practices must be checked to make sure they are in compliance with organic regulations. For instance, waxes with synthetic substances are not allowed in postharvest handling of organically certified fruit, and the shipping container must be labeled with the wax used (Suslow, 2000). In some cases, approval of treatments has not been done, such as in the use of ultraviolet light for sanitizing fruit surfaces. Guidelines of approved substances and a listing of compounds that may be approved for use can be found in the Federal Register (2005).

For processing operations, an organic systems plan (OSP) must be in effect. This plan is similar to Hazard Analysis and Critical Points (HAACP), but the critical points in an OSP are the recognition and elimination of places where nonorganic material contam- ination could occur (Plotto and Narciso, 2006). Processed organic products can be blended with nonorganic products, but the mixture no longer can be sold as $100 \%$ organic, and cannot carry the USDA organic label. Nevertheless there are four categories of organic products, depending on the amount of organic product present. They include 100\% organic, organic $(95 \%)$, made with organic ingredients ( $70 \%$ to $95 \%$ organic), and no organic (more than $70 \%$ nonorganic). In the arena of processing, the formulations and processing systems need to be verified by the Organic Materials Review Institute, because many areas of confusion and complication abound. In addition, import regulations for processed organic products differ from country to country, thus organic requirements of the perspective country should be checked before export (Plotto and Narciso, 2006).

As with conventional systems, surfaces used for fresh or processed product preparation should be kept clean. However, the cleaning agents can differ between organic and conventional systems. For instance, quaternary ammonia products are not allowed in organic systems on food contact surfaces because they leave a residual sanitizer (Plotto and Narciso, 2006; Suslow, 2000). Make sure all practices are documented as per standard sanitation operating procedure.

Food safety issues are a concern with all horticultural crops. In organic and conventional systems, use of animal manure or compost teas, although strictly regulated (Organic Foods Production Act of 2005), continues to pose safety issue concerns to consumers. In comparisons of organic and conventional production systems, the microbiological load was found to be more dependent on the crop than on the system (Mukherjee et al., 2004). Escherichia coli (not the O157:H7 serotype) prevalence in certified organic produce from samples taken across different commodities in Minnesota was not statistically 
different between organic versus conventional samples (Mukherjee et al., 2006).

\section{ANTIOXIDANTS, NUTRIENTS, AND PHYTOCHEMICALS}

Brandt and Mølgaard (2001) have challenged conventional thought by stating fruits and vegetables contribute to human health primarily through secondary metabolites, rather than through proteins, carbohydrates, or minerals. Secondary metabolites can be either helpful or harmful, depending on type and dosage. They may include the wellknown health-risking glycoalkaloids found in tomato and potato, or health-promoting flavonoids found in berries, as well as the well-known healthful carotenoids found in many fruits and vegetables. Antioxidants such a ascorbic acid, $\beta$-carotene, and phenolic compounds (flavonoids, flavones, phenolic acids) are considered plant-human healthbioactive compounds that are efficient scavengers of free oxygen radicals, or of free radicals with strong oxidizing power such as some carcinogens. In addition, some of the secondary metabolites, which also have antioxidant functions, are also considered vitamins or vitamin precursors, such as ascorbic acid (vitamin C) and $\beta$-carotene (provitamin A). Tests for individual antioxidant compounds, or an overall assessment of the antioxidant status of a fruit or vegetable can easily be determined using total phenolic content, oxygen radical absorbing capacity, thiobarbituric acid reactive substances, total

Table 1. Storage/treatments for postharvest organic produce allowed under the National Organic Program (Federal Register, 2006).

Storage treatments

Controlled-atmosphere (CA) storage (high $\mathrm{CO}_{2} /$ low $\mathrm{O}_{2}$ )

Low-temperature storage $\left(<5^{\circ} \mathrm{C}\right)$

Forced air cooling

High-temperature and CA storage for insect quarantine

Application of some volatiles (acetaldehyde, hydrogen peroxide)

Ethylene

Fumigants based on naturally occurring forms, and from natural sources

Waxes from carnauba or wood-extracted sources without synthetic substances

Sulfur dioxide

Sanitizers/Cleaners/Disinfectants

Chlorine (when used at or below current state and federal water quality standards)

Ozone

Hydrogen peroxide

Peroxyacetic acid

Acetic acid

Ethyl alcohol (must be from organic source)

CA, controlled atmosphere.

Table 2. Comparative tests reported for evaluating antioxidant status of organically and conventionally grown tree fruit (Lester et al., 2007; Woese et al., 1997; Zhao et al., 2006).

\begin{tabular}{llll}
\hline Minerals & Vitamins & \multicolumn{1}{c}{ Other } & \multicolumn{1}{c}{ Antioxidants/phytochemicals } \\
\hline $\mathrm{P}$ & Vitamin C & Protein & Beta carotene \\
$\mathrm{Ca}$ & Vitamin E & Dry matter & Lutein \\
$\mathrm{Mg}$ & Vitamin A & Sugar composition & Lycopene \\
$\mathrm{Nitrate}$ & B vitamins & Dietary fiber & Anthocyanins \\
$\mathrm{P}$ & & Acidity & Furanocoumarins \\
$\mathrm{Fe}$ & & Organic acids & Flavonoids \\
$\mathrm{Zn}$ & $\mathrm{pH}$ & Oxygen radical absorbing capacity \\
$\mathrm{Cu}$ & & Free amino acids & Ferric-reducing absorbing power \\
& & & Thiobarbituric acid reactive substances \\
& & & Total oxyradical scavenging capacity \\
& & & Total phenolic content \\
\hline
\end{tabular}

variables common to both production systems. The most common pitfalls are 1) using different cultivars; 2) using fruit from only one production system, generally the organic system to determine phytochemicals; and 3) using the same cultivar in each system, but systems are not matched for soil type, microenvironment, orchard age, or general production (e.g., irrigation) or harvest (e.g., fruit size, time of day, or position within the canopy) practices. Although it is acceptable to compare organically produced fruit with previously published values for conventionally grown fruit, it is cautioned that these values are only a reference and not a true comparison. Another potential pitfall in organic versus conventional comparisons is avoiding bias for or against organic systems.

When comparing produce, both pre- and postharvest variables need to be considered. When initiating a study, orchards should have the same variety, soil type, and age of trees. A sample size should be similar and preferably from a commercial orchard where inherent variation can be minimized because of the large number of trees. Fruit should be harvested at the same time, and replicates and location should be the same (e.g., trees in center of orchard vs. outside, shaded vs. sun fruit). Postharvest handling and treatments should be as similar as possible (same shading, packaging, storage temperature, humidity, light, and duration). DeEll and Prange (1992) did a comprehensive comparison of apples from conventionally and organically managed 'McIntosh' and 'Cortland' orchards that were located as closely to each other as possible, and held apples in storage with or without CA. They found that cultivar and storage significantly affected firmness regardless of production system. Sensory panelists were unable to detect significant differences in production method with regard to soluble solids content or titratable acidity after storage, and no difference in apple quality after storage was seen with production systems. Although not measured, it is possible that a component such as vitamin $\mathrm{C}$ or phenolic content was altered by the production system.

A scientific study example that matched common production and harvest variables, incorporated antioxidant tests was conducted using 'Rio Red' grapefruit, and provided multiple orchard harvests over the entire production period (Lester, 2006; Lester et al., 2007) with 2 years of harvests. This 'Rio Red' grapefruit study used orchards as similar as possible, with differences in production limited to those required for certified organic and conventional systems (Table 3 ). A summary of the published results is presented in Table 4. Organically produced grapefruit had smaller fruit; a thinner, greener peel; and a higher juice yield than conventional fruit. Although juice from organically grown grapefruit was higher in sugars, it was also higher in the bitter principle (naringin) and higher in acidity, and therefore rated more tart and less preferred by taste panelists. Ascorbic acid was higher, and 
Table 3. Factors in production systems of conventional and organic 'Rio Red' grapefruit orchards.

\begin{tabular}{lll}
\hline & \multicolumn{1}{c}{ Production System } \\
\cline { 2 - 3 } Factor & \multicolumn{1}{c}{ Organic } & \multicolumn{1}{c}{ Conventional } \\
\hline Continuous cropping (y) & Grapefruit & 18 \\
Previous crop & Rio Grande River & Citrus \\
Irrigation source & Compost & Rio Grande River \\
Fertilizer & Fishilizer & N-P-K, S \\
& Trace minerals & \\
Soil $(0-120 \mathrm{~cm})$ & Clay loam to silty clay; & Silty clay loam, clay loam; \\
& pH, 6.9 to 7.7 & pH, 7.2 to 8.0 \\
Weed control & Cultivation & Active Plus \\
& & Direx \\
Insect control & & Semazine \\
& Compost tea & Agrimek \\
& Flowable S & Citrus oil \\
& & Enable \\
& & Lorsban \\
& & Vendex \\
& & R-56 \\
\hline
\end{tabular}

Table 4. Statistically significant differences in 'Rio Red' grapefruit produced conventionally or organically (averaged for commercial early-, mid-, and late-season harvests) (Lester et al., 2007).

\begin{tabular}{lcc}
\hline & \multicolumn{2}{c}{ Significance (organic relative to conventional) } \\
\cline { 2 - 3 } Factor & External (peel) & Internal (juice) \\
\hline Fruit weight & Lower & - \\
Specific gravity & Higher & Higher \\
Peel thickness & Lower & \\
Color & & \\
$\quad$ Lightness & Higher & Higher \\
Chroma & Lower & Lower \\
Hue & Higher (more green) & Higher (more green) \\
Total N, NO $\mathrm{NO}_{3}$ & - & Lower \\
Juice yield (\%) & - & Higher \\
Ascorbic acid & - & Higher \\
Lycopene & - & Lower \\
Titratable acidity & - & Higher \\
pH & - & Lower \\
Total sugars & - & Higher \\
Soluble solids content & - & Higher \\
Consumer preference & - & More tart \\
$\quad$ Tartness & - & Less sweet \\
Sweetness & - & Less liked \\
Overall & - & \\
Phenol content & - & Higher \\
$\quad$ Flavonoid (Naringin) & - & Lower \\
Furanocoumarins & & Higher \\
Bergaptol & &
\end{tabular}

lycopene content lower, in organic juice when compared with conventional juice from fruit harvest at the same time. Lester et al. (2007) pointed out that ascorbic acid, lycopene, and sugars are all produced in the chloroplasts, with ascorbic acid synthesized from glucose, and lycopene synthesis occurring as chloroplasts break down to chromoplasts. Thus, the more green peel color of organic grapefruit indicates more chloroplasts, which means active photosynthesis producing more glucose to be converted to more ascorbic acid, and less lycopene because of more intact chloroplasts.

\section{SUMMARY}

Postharvest handling of fruit from organic orchards must be rethought and possibly retooled. Although the basics of orchard compound content and bioavailability, and consumer acceptance (sensory quality), all of which are areas of potentially critical scientific study.

\section{Literature Cited}

Bourne, E. and J. Prescott. 2002. A comparison of the nutritional value, sensory qualities, and food safety of organically and conventionally produced foods. Crit. Rev. Food Sci. Nutr. 47:1-34.

Brandt, K. and J.P. Mølgaard. 2001. Organic agriculture: Does it enhance or reduce the nutritional value of plant foods? J. Sci. Food Agr. 81:924-931.

DeEll, J.R. and R.K. Prange. 1992. Postharvest quality and sensory attributes of organically and conventionally grown apples. HortScience 27:1096-1099.

Federal Register. 2005. Docket no. TM-04-07. National Organic Program, Sunset Review. 116[70], 35177-35182. 1917.

Federal Register. 2006. Docket no. TM*04-01FR. National Organic Program. Amendments to the national list of allowed and prohibited substances (crops and processing). 175[71], 5329953303. 9-11-2006.

Lester, G. 2006. Organic versus conventionally grown produce: Quality differences, and guidelines for comparison studies. HortScience 41:296-300.

Lester, G.E., J. Manthey, and B.S. Buslig. 2007. Organic vs. conventionally grown 'Rio Red' grapefruit: Comparison of production inputs, market quality, consumer acceptance, and human health-bioactive compounds. J. Agr. Food Chem. 55:4474-4480.

Magkos, F., F. Arvaniti, and A. Zampelas. 2003. Organic food: Nutritious food or food for thought? A review of the evidence. Intl. J. Food Sci. Nutr. 54:357-371.

Mukherjee, A., D. Speh, E. Dyck, and F. DiezGonzalez. 2004. Preharvest evaluation of coliforms, Escherichia coli, Salmonella, and Escherichia coli $\mathrm{O} 157: \mathrm{H} 7$ in organic and conventional produce grown by Minnesota farmers. J. Food Prot. 67:894-900.

Mukherjee, A., D. Speh, A.T. Jones, K.M. Buesing, and F. Diez-Gonzalez. 2006. Longitudinal microbiological survey of fresh produce grown by farmers in the upper Midwest. J. Food Prot. 69:1928-1936.

Plotto, A. and J.A. Narciso. 2006. Guidelines and acceptable postharvest practices for organically grown produce. HortScience 41:287-291.

Suslow, T. 2000. Postharvest handling for organic crops. Univ. California. Publ. 7254:1-8, Univ. California, Oakland, CA.

Taiz, L. and E. Zeiger. 1998. Plant physiology, p. 347-376. 2nd ed. Sinauer Associates, Sunderland, MA.

Woese, K., D. Lange, C. Boess, and W. Bögl. 1997. A comparison of organically and conventionally grown foods: Results of a review of the relevant literature. J. Sci. Food Agr. 74:281-293.

Worthington, V. 2001. Nutritional quality of organic versus conventional fruits, vegetables and grains. J. Alt. Complementary Med. 7:161-173.

Zhao, X., E.E. Carey, W. Want, and C.B. Rajashekar. 2006. Does organic production enhance phytochemical content of fruit and vegetables? Current knowledge and prospects for research. HortTechnology 16:449-456. 